\title{
Evaluating the Practice of ICT-Based E-Leadership: The Experiences of Private-Based Secondary Teachers
}

\author{
https://doi.org/10.3991/ijet.v16i23.27437 \\ Lokman Mohd Tahir ${ }^{\bowtie}$, Chia Shi Ping, Noor Azean Atan, Mohd Fadzli Ali, \\ Sanitah Mohd Yusof \\ Universiti Teknologi Malaysia, Johore, Malaysia \\ p-lokman@utm.my
}

\begin{abstract}
In recent years, the role of internet and communication technology (ICT) has significantly impacted organisational activities including leadership practices. In this sense, interactions between leaders and followers have undergone tremendous technological changes that have reduced face-to-face interactions. Therefore, this study was designed to examine the implementation of using technological advances to develop an e-leadership platform for teachers and school leaders. A survey of the feedback from 260 in-service teachers currently with two private secondary schools was undertaken. Findings revealed that the school principals had used ICT-based e-leadership practices to conduct online meetings with teachers and disseminate relevant information on the school's administrative tasks. Most importantly, the principals have used e-leadership on a regular basis in planning and developing strategic school-improvement plans with teachers. As a result, the use of ICT-based e-learning has increased teachers' efficiency and performance and contributed to practical and effective school administration.
\end{abstract}

Keywords-e-leadership, ICT platform, private-based schools, implementation

\section{Introduction}

The advances in internet, communication and information technology (ICT) had led to changes in our daily activities and effectiveness of education system [1] where they have affected practices, teaching, and learning and transcend the ways in which schools are managed [2]. In Malaysia, the placement of ICT in local schools which was projected in 2013 has the potential to make a significant impact that will benefit teachers and school administrators $[3 ; 4 ; 25 ; 26 ; 27]$. As such, ICT plays a major role in determining the school's effectiveness in teaching, management, and leadership. Through this major decision, ICT has empowered the school leaders to enhance their indispensable role as technological leaders, which is considered central in managing their school $[5 ; 6 ; 25 ; 26]$.

In this sense, e-leadership was introduced as a mediator or platform for organisational leaders to practice their leadership or interact with their followers by using ICT $[7 ; 8 ; 9 ; 10]$ as the mediator for interaction and diminishing the face to face interaction 
due to geographical and time limitation. According to Avolio, Kahai, and Dodge (2001) [9], e-leadership is a social-influence process interceded by ICT to produce changes in attitudes, feelings, thinking, behavior, and/or performance with individuals, groups, and/or organisations. In addition, Avolio and Kahai (2003) [7] detailed that e-leadership practice will enhance the relationships among organisational members in a context in which work is mediated by technology. As such, Hinds and Kiesler (2002) [8] also defined e-leadership when a leader using computer mediation for task-oriented, decision-making, and problem-solving groups. Accordingly, the significant role played by educational technology is considered as a significant mediator between principals' leadership effectiveness and the overall school performance which can promote school effectiveness [11; 12] (Please refer Figure 1).

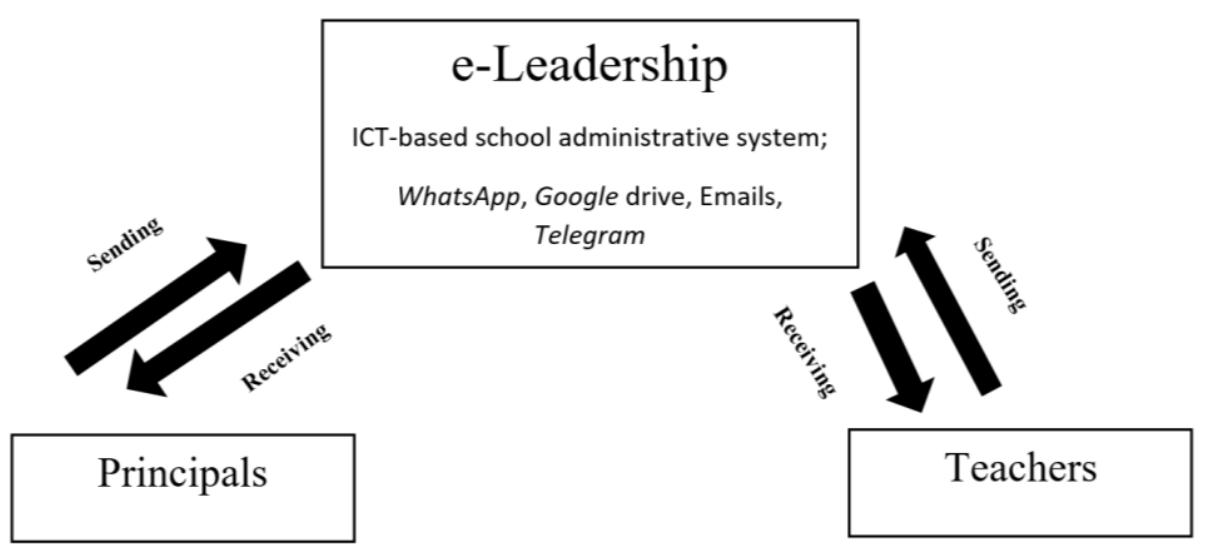

Fig. 1. Conceptualisation of e-leadership.

In school, Kashif and Ali (2019 [13] have mentioned that the significant role of school leaders in creating a school culture that enhances the use of ICT in schools is considered to be essential. In this sense, school leaders have a strong influence and are seen as the primary source of references to envision, implement, and create a school's culture through their encouragement and support for the enhancement of ICT $[14 ; 15]$. With the introduction of e-leadership in schools, the school principals would be able to practice their leadership characteristics by using ICT applications and platforms to provide guidance and support for teachers and staff [13; 16]. Later, this opinion is strengthened by Harris, Jones and Baba (2013) [17] who implied that the establishment of digital platforms within the school context makes it an appropriate time to discover and comprehend how ICT applications can be enacted and implemented to support school leadership practice.

\subsection{The practice of ICT-based e-leadership}

The broad perspective of e-leadership has attracted many research studies to examine the application of technology within organisational settings. However, previous studies mainly involved the business and management sectors [15]. Nevertheless, the 
use of ICT applications within the context of school leadership and management has been considered emerging in research.

At present, an initial study of e-leadership practice in schools known as 'e-schools' reported that the use of ICT in schools along with principals' ICT-supportive behaviors were significant predictors of school effectiveness and development [12]. These findings show that ICT is an essential mediator for school management and leadership in Croatia and Bosnia Herzegovina. Earlier, from the Malaysian perspective, Ibrahim $(2014 ; 2015)[18 ; 19]$ has statistically tested on the influence of e-leadership in intrateam communication on the job satisfaction of school leaders. The findings showed that school leaders in Malaysia frequently used their ICT applications, such as a cellular phone, to support their intra-team interactions. In addition, the intra-team variable was statistically recognised as a significant predictor of teachers' job satisfaction. In a study involving a sample of teachers at public schools in Hong Kong, Lam and Woodhead (2012) [20] compared the employment of ICT in public and independent schools. The findings indicate the provided positive feedback use of e-leadership practices has widely contributed to school-community connectedness and a culture of lifelong learning in studied schools. In Kashif and Ali (2019)'s study [13], it was concluded that school principals are facing challenges and barriers in the use of ICT in schools due to their difficulties in understanding its potential effects.

From a study in Norwegian schools, Ottestad (2013) [21] has surveyed principals' adoption of distributed, transformational, and pedagogical leadership using an ICT platform. The survey was conducted in 2009 with 247 school leaders and 386 teachers from primary and lower secondary schools. Based on the findings, it was noted that the four sub-constructs of school leadership using ICT: digital practice, ICT maturity, assessment and roles involving ICT, and leadership collaboration correlated with teachers' attitudes and the amount of time spent using ICT for administration. However, regression analyses identified three sub-constructs as weak predictors on the amount of time teachers spent with computers for their teaching practices. Nevertheless, the role of assessment using ICT and digital practice has a strong impact on teachers' time spent on computers for teaching practices. However, leadership for collaboration strongly predicted teachers' use of ICT for administrative purposes followed by digital practice. In Pollock and Hauseman (2019)'s study, the use of and emails provides many benefits to Canadian principals working lives especially communicating efficiently with teachers and school stakeholders. However, the principals revealed that an overload of emails has contributed to their heavy workload and made their job more difficult. In Akram and Khan (2020)'s [23] study, they found that the LMS system had indeed provided principals with extensive support in managing and leading their schools allowing them to monitor teaching and learning, make decisions, and communicate within the school's e-leadership system.

To date, previous research in Malaysia that focused on the implementations or practices related to ICT-based e-leadership is considered to be limited and worthy of further study from a local perspective. Second, especially under-represented were the perspectives of teachers working in or from private schools in Malaysia. Thus the aim of the present study is designed to: (a) identify the elements within e-leadership platforms that 
are frequently employed by principals; (b) enquire whether there are significant differences in feedback on using ICT in their schools based on teachers' demographics.

\section{Methodology}

This survey by design study involved feedback from distributed questionnaire and a small scale interview's transcripts from private secondary school teachers. In answering this questionnaire, a total of 260 teachers in private secondary schools were involved. The return rate was $86 \%$, which is acceptable for a survey of this type. Teachers were randomly selected and asked to provide their feedback on the survey items within two working weeks. As for the interview session, six teachers were also selected through purposive sampling for the interviews. Purposive sampling was applied to get more detailed information and to fill up any non-response gap in the quantitative phase. All teachers involved were in-service secondary school teachers in Malaysian private schools with wide experiences in practicing e-leadership based on their internet-based interactions with their principals.

\subsection{Instruments}

The closed questionnaire consists of 10 items in three major sections. In section A, there are 3 items asking teachers for their demographic/background information (gender, age and teaching experience). In section B, there are 7 items which seek information on implementation of ICT in schools. All teachers were asked to give their reactions based on the relevant items using a five-point Likert scale: 1 - strongly disagree to 5 - strongly agree except for the demographic items which used nominal scales.

All items were in Malay language for easier understanding by the all teachers involved. Some of the items are adopted from previous studies of ICT-based e-leadership $[13 ; 18 ; 23]$ all of which measured the significant implementation and practices of using the ICT-based e-leadership from various educational systems. All items had undergone a rigorous forward and backward translation process [24] by two translators. A Malay language expert and a few teachers were approached in order to ensure the precision of the Malay language items. Items were also translated into English language using a backward approach with the help of language experts. Before proceeding with the pilot study, items were checked by three experts in school leadership and educational technology to ensure the precision of the meaning, sentence structure, and the relevance of the items. Before proceeding with the actual data collection, all items were piloted to ten selected in-service public secondary teachers.

Table 1. Questionnaire items.

\begin{tabular}{|l|c|c|}
\hline \multicolumn{1}{|c|}{ Contents } & Descriptions & Total items \\
\hline $\begin{array}{l}\text { Demographics } \\
\text { (Section A) }\end{array}$ & Gender, teaching experience, and age. & 3 items \\
\hline $\begin{array}{l}\text { The e-leadership practices in private- } \\
\text { based schools. (Section B) }\end{array}$ & $\begin{array}{c}\text { Use of information and communication technology } \\
\text { (ICT) tools by principals. }\end{array}$ & 7 items \\
\hline
\end{tabular}


The reliability of the internal consistency of this study was obtained using Cronbach's alpha value. After collecting the data from the pilot test, the Cronbach's alpha for all 24 items was tabulated giving a value of 0.703 which indicates high homogeneity between the items and confirms that it is reliable to use them to measure the teachers' feedback data.

In addition, the semi-structured interview protocol with teachers was also being developed to obtain in-depth explanations of the use of ICT-based e-leadership in the studied private secondary schools. Through the semi structured interviews, the researcher was able to obtain rich in-depth information on teachers' experiences using the e-leadership and allow them to deliver their opinions [26]. During the interview sessions, we asked questions such as: (a) Does your school principal use ICT and eleadership while communicating, interacting, and sharing files and documents with you?

\subsection{Data analysis}

All data are presented using a descriptive analysis giving means, standard deviations, and percentages. In determining the benefits and implementation of ICT-based e-leadership, all mean scores for each item that represented the constructs were totaled and later divided by the number of items within each construct to obtain the mean score for each construct. In measuring the differences based on teachers' demographics, an inferential $t$-test with gender of the teachers was employed. In addition, the One-way Analysis of Variance (ANOVA) test is also used to analyse the ICT-based e-leadership based on the teachers' feedback. The interview data was analysed using the qualitative analysis. First, data was re-read several times to obtain the verbatim meanings. Lastly, the transcripts were matched and refer to the research questions.

\section{$3 \quad$ Findings}

\subsection{Teachers' demographics}

The distribution of the demographics of the in-service secondary teachers is shown on the gender of the serving teacher respondents: Male $=62 ; 23.8 \%$; Female $=198$; $76.2 \%$. As for length of teaching experience, a majority of in-service secondary teachers had less than 5 years' experience $(\mathrm{N}=78 ; 30 \%)$ followed by 6 to 10 years of experience $(\mathrm{N}=75 ; 28.3 \%)$ and from 11 to 15 years $(\mathrm{N}=45 ; 17.3 \%)$. A total of 31 teachers had 16 to 20 years of teaching experience $(\mathrm{N}=31: 11.9 \%)$ with 31 teachers having more than 21 years $(11.9 \%)$. The age ranges were: $7(2.7 \%)$ aged 25 years and below; $74(28.5 \%)$ aged 26 to 30 years; the same distribution, $74(28.5 \%)$, were aged 31 to 35 years; 43 teachers $(16.5 \%)$ were aged 36 to 40 years; and 62 teachers $(23.8 \%)$ were aged 41 years and above. 


\subsection{The ICT applications for e-leadership practices}

In identifying the ICT applications widely used by the school principals for e-leadership practices, teachers were asked to select the ICT applications frequently used by their principals. The teacher feedback was descriptively analysed. Teachers were allowed to choose more than one option. Descriptively, Figure 2 and Table 2 show feedback provided by teachers at the private secondary schools. Here, 212 teachers $(81.5 \%)$ chose WhatsApp as the ICT-based e-leadership platform most frequently used by their principals to organize online interactions with teachers such as for sharing and circulating school information, school planning, and school administrative tasks. Next, Google Drive was identified by 182 teachers $(70 \%)$ as the second most frequent ICT tool used by school principals. Third, a total of 169 teachers $(65 \%)$ chose Telegram as the ICT-based application third most frequently used by school principals with teachers in their schools. Next, 114 teachers $(43.8 \%)$ indicated that their principals used the school email system to communicate and disseminate information to teachers. In addition, 78 teachers $(30 \%)$ indicated that their principals used custom-made school management systems, followed by 71 teachers $(27.3 \%)$ who indicated that their principals had used the school's internal storage server while leading their schools. Finally, only 8 teachers $(3.1 \%)$ chose other ICT-based tools that were used by their principals for school management purposes, such as Google Classroom, Google Calendar, video call applications, and the school's websites and blogs.

Table 2. ICT applications frequently used by principals for e-leadership practices

\begin{tabular}{|l|c|c|}
\hline \multicolumn{1}{|c|}{ The ICT applications } & Frequency & Percent \\
\hline WhatsApp. & 212 & 81.5 \\
\hline Google Drive. & 182 & 70.0 \\
\hline Telegram. & 169 & 65.0 \\
\hline The school's emails. & 114 & 43.8 \\
\hline Bespoke school management systems. & 78 & 30.0 \\
\hline Internal storage server. & 71 & 27.3 \\
\hline $\begin{array}{l}\text { Others: Google Classroom, Google Calendar, video call } \\
\text { applications, websites and blogs. }\end{array}$ & 8 & 3.1 \\
\hline
\end{tabular}

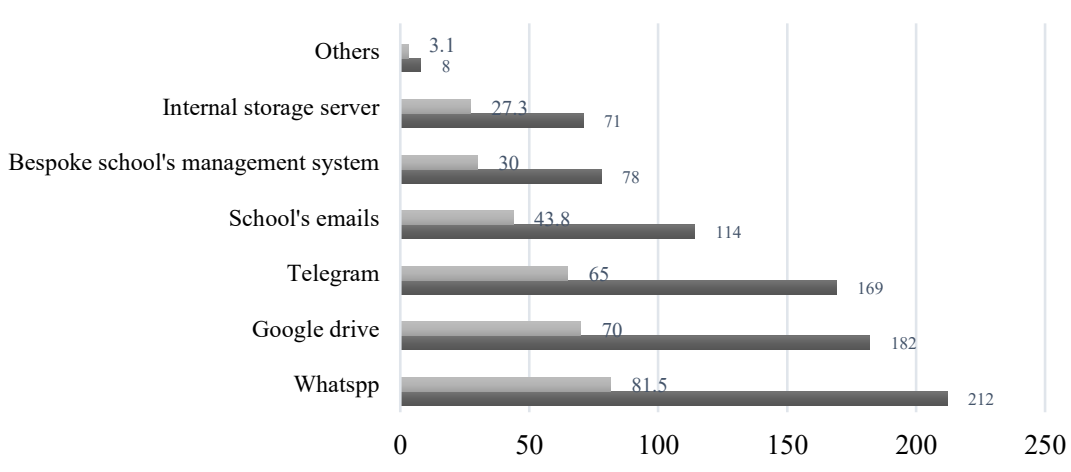

Fig. 2. ICT applications used by principals for e-leadership practices 
Following the acquisition of the quantitative data, interview sessions were conducted with six teachers who actively interacted with their principals using ICT-based e-leadership applications. Data revealed the use of various applications by the principals in carrying out their e-leadership practices. They frequently used WhatsApp, online conference tools, Telegram, email, the school management system, the school server, Google Sheets, Google Docs, Google Classroom, Google Drive, Google Forms, and Google Calendar to complete the school's routine management tasks. Transcripts obtained from four teachers are presented in the following:

"Our school has been using Google Classroom as a centralized system for management and administration related works such as uploading various forms and daily lesson plans. I would say it is much more efficient compared to the traditional ways. We used to write daily lesson plans and hand them up to the principals for checking. Such a process would take a day or two whilst using Google Classroom enables the process to take up less than two hours. Efficiency is highly improved. Google classroom is used for management. A WhatsApp group is used for faster transmission of information. Online conference tools are used for meetings." (T1).

"We normally use WhatsApp to communicate with each other. Sometimes, we use Zoom and Google Meet to do video calls for a better two-way communication as well. Google Classroom and Google Drive are being used for document sharing. " (T2)

"We usually use Telegram, Google Meet, Google Forms and email in the school. Our principal will use email, WhatsApp and Telegram to coordinate programs and give instructions. Sometimes, we also use online meeting apps like Google Meet to discuss important matters with school administrators and teachers. When there is a need to do evaluation, we will use Google Forms to do evaluation such as learning-walk evaluation." (T3).

"There are a lot of e-leadership tools that have been implemented in my school. For example, my school is using Telegram and WhatsApp for information sharing and assigning work purposes. Other than that, my school is also using a school management system to record student and teacher attendance, student discipline records, student results, etc." (T6).

\subsection{Teachers' demographics significant differences}

In order to investigate whether there are meaningful differences based on teachers' demographics, the inferential differentiation tests - the $t$-test and analysis of variance (ANOVA) - are used. Before proceeding with these tests, all data were tested at a significance of 0.05 and a $95 \%$ confidence level.

Table 3. Results of t-test analysis based on teachers' gender

\begin{tabular}{|l|c|c|c|c|c|}
\hline \multicolumn{1}{|c|}{ Gender } & N & Means & SD & t-value & Sig. \\
\hline Male & 62 & 2.55 & 1.327 & 1.113 & .258 \\
\hline Female & 198 & 2.76 & 1.290 & & \\
\hline
\end{tabular}

$\mathrm{N}=260$; Significance level at $\mathrm{p}<0.05$ 
First, the $t$-test reveals that there are no significant differences in terms of teachers' gender on the employment of ICT-based leadership practices in studied schools $[t$ (260) $=1.113 ; p=0.258]$. However, despite these $t$-test results, data showed that female teachers have a much higher level of positive perception $(\bar{X}=2.75)$ on the employment of ICT-based leadership compared to their male counterparts $(\bar{X}=2.55)$. Furthermore, teachers' years of teaching experience were also inspected using the ANOVA test. The findings indicate that teachers' teaching experience and age have significant differences in terms of their perceptions towards the employment of ICT-based leadership in their schools: age $\left(F_{(4,255)}=15.601 ; p=0.00\right)$ and teaching experience $\left(F_{(4,255)}=11.717 ; p=\right.$ $0.00)$. In general, for teachers' teaching experience, the Tukey's post hoc analysis indicates that senior and experienced teachers who have been working in private secondary schools have higher mean scores and have positive perceptions of the use of ICT-based leadership compared to junior and less experienced teachers. In this finding, teachers who have more than 21 years of teaching experience $(\mathrm{M}=3.80)$ have higher mean scores followed by teachers who have 16 to 21 years' experience $(M=3.32)$. Surprisingly, teachers with between 6 to 10 years' experience $(M=2.25)$ have the lowest mean scores compared to other teacher clusters.

Table 4. ANOVA analyses of teachers' age and teaching experiences

\begin{tabular}{|l|c|c|c|c|c|}
\hline \multicolumn{1}{|c|}{ Variables } & df & SS & MS & F & Sig \\
\hline Between groups & & & & & \\
\hline Within groups & 4 & 67.904 & 16.976 & 11.717 & $0.00^{*}$ \\
\hline Total Age & 255 & 369.461 & 1.449 & & \\
\hline \multicolumn{1}{|c|}{ Agence } & 259 & 437.365 & & & \\
\hline Between groups & & & & & \\
\hline Within groups & 4 & 83.584 & 20.896 & 15.601 & $0.00 *$ \\
\hline Total & 255 & 353.781 & 1.387 & & \\
\hline
\end{tabular}

$\mathrm{N}=260$; Significance level at $p<0.05$

Table 5. Tukey's post-hoc analyses of teachers' age and teaching experiences.

\begin{tabular}{|c|c|c|c|}
\hline (I) Experiences & (J) Experiences & MD (I-J) & Sig. \\
\hline above 20 years & 1 to 5 years & 1.191 & $0.00^{*}$ \\
\hline & $6-10$ years & 1.553 & $0.00^{*}$ \\
\hline & $11-15$ years & 1.340 & $0.00 *$ \\
\hline (I) Age & $16-20$ years & .484 & 0.501 \\
\hline Above 40 years & $(\mathbf{J})$ Age & MD (I-J) & Sig. \\
\hline & 23 to 25 years & 0.07 & 1.00 \\
\hline & $26-30$ years & 1.36 & $0.00^{*}$ \\
\hline & $31-35$ years & 1.31 & $0.00 *$ \\
\hline
\end{tabular}

$\mathrm{N}=260 ; \mathrm{MD}=$ Mean Differences; Significance level at $p<0.05$ 
Based on Tukey's post hoc results, significant differences were indicated based on three pairs of teaching experience: 21 years and above with 11 to 15 years $(\mathrm{MD}=0.281$; $\mathrm{p}=0.00)$, 5 years and below $(\mathrm{MD}=1.191 ; \mathrm{P}=0.00)$ and 6 to 10 years $(\mathrm{MD}=1.553$; $\mathrm{p}=0.00)$ and 11 to 15 years $(\mathrm{MD}=1.340 ; \mathrm{p}=0.00)$. Comparison with teachers who are 25 years and below indicated a non-significant findings based on results from the Post Hoc analysis. In terms of teachers' age, there are also three pairs that have significant differences, which are teachers who are 41 years and above with teachers who are 26 to 30 years old $(\mathrm{MD}=1.36 ; \mathrm{p}=0.00), 31$ years old to 35 years old $(\mathrm{MD}=1.31 ; \mathrm{P}=0.00)$ and lastly with 36 to 40 years old $(\mathrm{MD}=1.04 ; \mathrm{p}=0.00)$. As for comparison with teachers' age of 25 years and below, the post hoc analysis shown non-significant finding.

\section{Discussion}

This study is considered very significant in determining Malaysian teachers' perceptions of ICT-based e-leadership which has been under-explored within Malaysian schools. In terms of principals' use of ICT-based e-leadership practices, three major ICT-based platforms: WhatsApp, Telegram, and Google Drive were selected by teachers as the ICT-based applications most frequently used by their school principals for sharing and disseminating information to all teachers in their respective schools. At the same time, their school principals also used their ICT-based e-leadership platforms within the school's management and leadership tasks such as to monitor students' academic progress, plan the school's meetings, generate examination schedules, and decide on annual school events. These platforms also have advantages for school budgeting and financial management which require ICT-based applications for storage and the dissemination of financial procedures to all private-school principals. In this study, teachers also indicate that the principals truly understand the effective use of ICT to execute e-leadership practices within their schools. However, the findings were incongruent with Kashif and Ali (2019) [13] whom points out that school principals were frequently facing challenges and barriers when using ICT in schools due to their lack of understanding of its potential effects. In this research, the principals in the studied schools valued the importance of ICT as a principal driver within the school leadership practices; in addition, principals were also aware of the effectiveness of ICT or e-leadership technology as a support for the school's decision-making, planning, and control processes, which certainly helps and facilitates their school administrative tasks.

Tests show that there are significant differences in teacher's perceptions of using the ICT-based applications within their respective schools based on teaching experience and age. These show that senior teachers had a much higher level of positive perception compared with four other teacher experience clusters. Overall measurement of significant differences based on years of experience show that seniority as an educator suggests significant differences related to the implementation of ICT-based applications in their schools. Ultimately, this research has provided evidence on the e-leadership findings of school principals in the under-studied area of private secondary schools. In this study, private school principals had frequently used e-leadership platforms to lead their schools towards excellence. Thus, the principals were enthusiastic users of e-leadership 
to communicate, disseminate, and share information and to store school documentation and files within an ICT repository system. For teachers, the frequent use of e-leadership has provided them with more immediate responses as they could easily access the school documentations and information to complete their assignments and tasks. In addition, through the e-leadership platform, their documents and records can be saved digitally and can be shared among colleagues through the use of ICT platforms.

\section{Acknowledgement}

The authors would like to thank the Research Management Centre (RMC) at Universiti Teknologi Malaysia (UTM) for funding this project under grant of Fundamental Research with vot number PY/2019/01602: Q. J130000.2553.21H34.

\section{References}

[1] Demir, K. (2006). School management information systems in primary schools. The Turkish Online Journal of Educational Technology, 5(2): 32-45.

[2] Tan, C. (2016). Technology usage in school management: Electronic school. International Journal of Learning and Teaching, 2(1): 53-57.

[3] Ministry of Higher Education, Malaysia. (2013). Malaysian Education Blueprint 2013 2025 (Preschool to Post-Secondary Education). Putrajaya: Ministry of Education. https://doi.org/10.30880/jtet.2019.11.01.004

[4] Al-Hajri, R.M.S. (2007). Teachers' belief and self-efficacy in computer technology integration for teaching and learning: A comparative study between Oman and Malaysia. Unpublished PhD Thesis, School of Education, Universiti Sains Malaysia.

[5] Al-Harthi, A.S.A. (2017). Technological self-efficacy among school leaders in Oman: A preliminary study. Journal of Further and Higher Education, 41(6): $760-772$. https://doi.org/10.1080/0309877x.2016.1177168

[6] Weng, C.H., \& Tang, Y. (2014). The relationship between technology leadership strategies and effectiveness of school administration: An empirical study. Computers \& Education, 76: 91 - 107. https://doi.org/10.1016/j.compedu.2014.03.010

[7] Avolio, B. J., Kahai, S. S., \& Dodge, G. E. (2001). E-leadership: Implications for theory, research, and practice. Leadership Quarterly, 11:615- 668. https://doi.org/10.1016/s10489843(00)00062-X

[8] Hinds, P., \& Kiesler. (2002). Distributed work. Cambridge, Massachusetts: MIT Press.

[9] Avolio, B. J., \& Kahai, S. S. (2003). Adding the "E" to e-leadership: How it may impact your leadership. Organizational Dynamics, 3(4): 325-338. https://doi.org/10.1016/s00902616(02)00133-X

[10] Carreño, I.D.V.G. (2014). Emergent leadership: E-leadership implications for virtual education. Revista de Estudios Para El Desarrollo Social de La Comunicación, 10: 308-324. https://doi.org/10.15213/redes.n10.p309

[11] Shah, M. (2014). Impact of management information systems (MIS) on school administration: What the literature says. Procedia-Social and Behavioral Sciences, 116: 2799-2804. https://doi.org/10.1016/j.sbspro.2014.01.659

[12] Alfirević, N., \& Petković, S. (2017). E-school development and quality of management and leadership in educational systems in Croatia and Bosnia \& Herzegovina. Paper presented at 
The Twelfth International Conference of Innovative Responses for Growth and Competitiveness (pp. 261-274). May 17th-19th, Split-Bol, Brač, Croatia.

[13] Kashif, M.N.U., \& Ali, M.N. (2019). E-Leadership: Secondary school heads and contemporary needs. International Journal of Distance Education and E- Learning. 4(2): 18 - 25.

[14] Oh, S.P. \& Chua, Y.P. (2018). An explorative review of e-leadership studies, International Online Journal of Educational Leadership, 2(1): 4-20

[15] Mishra, P., Henriksen, D., Boltz, L. O., \& Richardson, C. (2016). E-leadership and teacher development using ICT. In R. Huang, Kinshuk, \& J. K. Price (Eds.), ICT in Education in Global Context (pp. 249-266). Springer Berlin Heidelberg. https://doi.org/10.1007/978-3662-47956-8 13

[16] Herring, M.C., Koehler, M.J., \& Mishra, P. (Eds.). (2017). Handbook of Technological Pedagogical Content Knowledge (TPACK) for Educators. (2nd edition). New York: Routledge. https://doi.org/10.1007/s11528-017-0176-2

[17] Harris, A. Jones, M. \& Baba, S. (2013). Distributed leadership and digital collaborative learning: A synergistic relationship? British Journal of Educational Technology. 44(6): 926939. https://doi.org/10.1111/bjet.12107

[18] Ibrahim, M.Y. (2014). Model of e-leadership, intra-team communication and job satisfaction among school leaders in Malaysia. Mediterranean Journal of Social Sciences, 5(23), $1927-$ 1931. https://doi.org/10.5901/mjss.2014.v5n23p1927

[19] Ibrahim, M.Y. (2015). Model of virtual leadership, intra-team communication and job performance among school leaders in Malaysia. Procedia - Social and Behavioral Sciences, 186, 674-680. https://doi.org/10.1016/j.sbspro.2015.04.126

[20] Lam, P. H. C., \& Woodhead, P. (2012). A critical analysis of the challenges facing e-leaders in the 21 st century: A review and comparison of the information and communication technology development of a public school and a public independent school in Hong Kong. International Journal of Learning, 18(3), 131-146. https://doi.org/10.18848/14479494/cgp/v18i03/47537

[21] Ottestad, G. (2013). School leadership for ICT and teachers' use of digital tools. Nordic Journal of Digital Literacy, 8 (1-2): 107-125. https://doi.org/10.18261/issn1891-943x2013-01-02-07

[22] Pollock, K., \& Hauseman, D.C. (2019). The use of e-mail and principals' work: A doubleedged sword. Leadership and Policy in Schools, 18(3): 382-393. https://doi.org/10. $1080 / 15700763.2017 .1398338$

[23] Akram, M., \& Khan, A. M. (2020). Exploring e-leadership of principals: Increasing school effectiveness by learning management system. Journal of Education \& Social Sciences, 8(1): 15-30. https://doi.org/10.20547/jess0812008102

[24] Sperber, A.D., DeVellis, R.F., \& Boehlecke, B. (1995). Cross cultural translation. Journal of Cross-Cultural Psychology, 25(4): 501. https://doi.org/10.1177/0022022194254006

[25] Edwards, R., \& Holland, J. (2013). What is interviewing? London: Bloomsbury.

[26] Razak, N.A., Ab Jalil, H., \& Ismail, I.A. (2019). Challenges in ICT Integration among Malaysian public primary education teachers: The roles of leaders and stakeholders. International Journal of Emerging Technologies in Learning, 14(24): 184- 205. https://doi.org/ 10.3991/ijet.v14i24.12101

[27] Mohamad Said, M.N.H., Mohd Tahir, L., Ali, M.F., \& Megat Zakaria, M.A.Z. (2015). ICT Literacy and readiness in using computers among head teachers in their tertiary learning experiences and school management tasks. International Journal of Emerging Technologies in Learning, 10(2): 63- 69. https://doi.org/10.3991/ijet.v10i2.4405

[28] Gamba, S.A., Byabazaire, Y., \& Busthami, A.H. (2018). Toward the use of 21st century teaching-learning approaches: The trend of development in Malaysian schools within the 
Paper -Evaluating the Practice of ICT-Based E-Leadership: The Experiences of Private-Based ...

context of Asia Pacific. International Journal of Emerging Technologies in Learning, 10(4): 72- 79. https://doi.org/10.3991/ijet.v10i4.4717

\section{$7 \quad$ Authors}

Lokman Mohd Tahir, is with School of Education, Universiti Teknologi Malaysia, Johore, Malaysia.

Chia Shi Ping, is with School of Education, Universiti Teknologi Malaysia, Johore, Malaysia.

Noor Azean Atan, is with School of Education, Universiti Teknologi Malaysia, Johore, Malaysia.

Mohd Fadzli Ali, is with School of Education, Universiti Teknologi Malaysia, Johore, Malaysia.

Sanitah Mohd Yusof, is with School of Education, Universiti Teknologi Malaysia, Johore, Malaysia.

Article submitted 2021-10-04. Resubmitted 2021-10-23. Final acceptance 2021-10-23. Final version published as submitted by the authors. 